Article

\title{
Expanding Australian Indigenous Entrepreneurship Education Ecosystems
}

\author{
Alex Maritz ${ }^{1, *}$ and Dennis Foley ${ }^{2}$ \\ 1 Department of Entrepreneurship, Innovation and Marketing, La Trobe University, \\ Bundoora VIC 3086, Australia \\ 2 School of Management, University of Canberra, Bruce ACT 2617, Australia; dennis.foley@canberra.edu.au \\ * Correspondence: a.maritz@latrobe.edu.au
}

Received: 17 March 2018; Accepted: 3 June 2018; Published: 6 June 2018

\begin{abstract}
Australian Indigenous entrepreneurship and entrepreneurship education represents a significant opportunity for Indigenous people to enhance their entrepreneurial skills, in turn building vibrant Indigenous-led economies that support sustainable economic development and social well-being. This study is the first of its kind to explore the conceptualization of a framework of Australian Indigenous entrepreneurship education ecosystems. The purpose is to provide emergent inquiry and participatory action research into entrepreneurship education ecosystems, enabling the expansion of Indigenous research and practice; with the objective of delineating specific fundamentals associated with Indigenous entrepreneurs, such as limitations in social, human, and financial capital. We include and integrate Australian Indigenous value perspectives, including Indigenous knowledge, wisdom, and resilience, as well as the cultural captivity of entrepreneurship and Indigenous culture. The addition to the body of knowledge provides practical implications and a framework to the benefit of all ecosystem participants, including entrepreneurship educators, Indigenous entrepreneurs, policy-makers, training suppliers, and dynamic institutional participants, such as incubators, accelerators, and community development initiatives.
\end{abstract}

Keywords: Australian Indigenous entrepreneurship; entrepreneurship education; and entrepreneurship education ecosystems

\section{Introduction}

Australian Indigenous entrepreneurship research and practice has received somewhat scant and under-researched exposure and prominence when compared to mainstream (non-Indigenous) entrepreneurship (Bodle et al. 2018; Colbourne 2018; Fuller et al. 2014; Foley 2013). This is particularly the case when considering Indigenous entrepreneurship education and entrepreneurship education ecosystems (Anderson et al. 2006; Bajada and Trayler 2014; Foley 2006; Maritz 2017; Belitski and Heron 2017). This study is a first of its kind to explore the conceptualization of a framework of Australian Indigenous entrepreneurship education ecosystems (IEEE).

Whilst the literature on mainstream entrepreneurship and ecosystem integration has developed significantly over the past decade or two, this has not been the case within the context of Indigenous entrepreneurship (Roundy 2017; Foley 2017). Foley (2012) postulates that Australian Indigenous entrepreneurship is fundamentally flawed, in that most initiatives are not developed or implemented by Indigenous people. Since indications are that the experiences of Indigenous entrepreneurs are markedly different to the mainstream or non-Indigenous entrepreneur (Foley 2006; Wood and Davidson 2011), the social and economic disadvantages confronted by many Indigenous Australians are well-known and understood (Bajada and Trayler 2014), it stands to reason that the entrepreneur and ecosystem integration will also be markedly different. Furthermore, studies have highlighted 
significant value differences when comparing traditional management education and Indigenous education (Verbos et al. 2011), highlighting the need for specific IEEEs. This is the motivation to proceed with this study, using emergent inquiry and action research as guiding methods.

To further amplify the dimensions of Indigenous entrepreneurship, Colbourne (2018) identified unique descriptions associated with dimensions like community, spirituality, and sustainability. He even placed emphasis on a re-definition of entrepreneurship from the perspective of Indigenous community and its particular socioeconomic organization, incorporating a unique blend of Indigenous economic and socio-ecological factors. These inferences often associate with social entrepreneurship (Roundy 2017; Anderson et al. 2006). The context of Australian Indigenous entrepreneurship includes both the community-based "business" or undertaking, the community-based not-for-profit delivering a service, and the commercial capitalist enterprise (Foley and Hunter 2013). For the purpose of this paper, we have simplified all of these different enterprises, as they all strive for Indigenous economic and socio-ecological improvement, and all adhere to the principles of IEEE.

This research comes at a good and opportune time, identifying that the Australian Indigenous unemployment rate sits at just 46 percent, 36 percent in remote areas (KPMG 2016). The notion of stimulating the growth and success of Indigenous businesses, thereby creating employment and adding economic and social value (Foley 2008a) is a proposed outcome, of this study. The link to IEEEs mirrors the correlation of an increase in Indigenous employment with higher levels of education (Spencer et al. 2016), notwithstanding outcomes associated to cultural captivity of entrepreneurship (Paredo and Mclean 2010), inclusive development (Verbos et al. 2011), Indigenous knowledge (Fitzgibbons and Humphries 2011), and Indigenous wisdom (Verbos and Humphries 2015).

We commence the study with an overview of Australian Indigenous entrepreneurship, followed by an overview of entrepreneurship education (EE) and entrepreneurship education ecosystems (EEE). We then integrate these overviews with a discussion on the contextualization of Indigenous entrepreneurship and ecosystems, with the aim of developing a conceptual framework for IEEEs. The purpose is to provide conceptualization and emergent inquiry into IEEEs, enabling the expansion of Indigenous research and practice. The objectives of this paper are to delineate specific Australian Indigenous entrepreneurs' challenges in areas such as social, human, and financial capital, aligned to expanding IEEEs, thereby integrating Indigenous value perspectives, including knowledge, wisdom, resilience, cultural captivity, and culture. The addition to the body of knowledge will provide practical implications to the enhancement of economic and social benefits to nascent and experienced Indigenous entrepreneurs.

\section{Indigenous Entrepreneurship}

There is a plethora of definitions on entrepreneurship; some accounts of entrepreneurship have tried to define it within the mindset of an objective lens that considered monetary considerations based on profits (Dana 2007). Indigenous Entrepreneurship, however, is different, for there are many complicated social and political influences that are present in the environment of the Indigenous entrepreneur; profit is not a dominant motivator (Foley 2000, 2006, 2008a). Leo-Paul Dana, in his 2007 publication, was influenced by the Global Enterprise Monitor definition; however, this fails to understand the Indigenous standpoint. Dana simply states:

$\ldots$ any type of entrepreneurial initiative, including self-employment. Indigenous nations are people whose ancestors were living in an area prior to colonisation, or within a nation state, prior to the formation of a nation state, and so I broadly define indigenous entrepreneurship as self-employment based on indigenous knowledge (Dana 2005, 2007, p. 4).

This definition is far too simplistic, denying social, cultural and historical impediments.

Another widely accepted definition, written and defined from a colonial, non-Indigenous lens based on Canadian writings, attempting to include almost every scenario, is that of Hindle and Lansdowne, who wrote: 
Indigenous entrepreneurship is the creation, management and development of new ventures by Indigenous people for the benefit of Indigenous people. The organisations thus created can pertain for the benefit of Indigenous people. The organizations thus created can pertain to either the private, public or non-profit sectors. The desired and achieved benefits of venturing can range from the narrowing view of economic profit for a single individual to the broad view of multiple, social and economic advantages for entire communities. Outcomes and entitlements derived from Indigenous entrepreneurship may extend to enterprise partners and stakeholders who may be non-indigenous (Hindle and Lansdowne 2005, p. 132).

A definition that predates both Dana and Hindle (Foley 2000, 2008b), which is based on empirical evidence following qualitative case study analysis, is that of Foley, who wrote:

The Indigenous Australian entrepreneur alters traditional patterns of behaviour, by utilizing their resources in the pursuit of self-determination and economic sustainability via their entry into self-employment, forcing social change in the pursuit of opportunity beyond the cultural norms of their initial economic resources (Foley 2000, 2008b, p. 11).

For the purposes of this paper, we have adopted the Foley $(2000,2008 b)$ definition, as it is written from an Indigenous standpoint based on empirical evidence, and is both robust and pertinent to the business environment of the Indigenous entrepreneur, be it city-, regional-, or rural remote-based. We interchangeably refer to Indigenous entrepreneurs and Australian Indigenous entrepreneurs, with the contextual inference that Australian Indigenous entrepreneurs are examples of global Indigenous entrepreneurs.

Based on previous research (Foley 2006), the following comparative has been drawn, summarising findings from over one and a half decades of research, looking predominantly at networking aspects and differences that highlight the negative positioning within society that Indigenous Australians commence business from.

Seven key dimensions were found that distinguish approaches to entrepreneurial networking adapted by entrepreneurs in the two comparative cultures: drivers for activation of relationship, view of network, role of family, dynamics, diversity, business relations, and the relationship between social and business spheres.

Non-Indigenous people have seen networking as a continuation of their cultural norms and associations, whereas the Indigenous Australians have seen it as an essential business tool to succeed within the dominant society. Networking has been seen by the non-Indigenous as culturally acceptable and encouraged. The Indigenous have seen it as a necessity in business; however, family members in general did not understand Aboriginal networking with non-Aboriginal, and in some cases attempted to sabotage or diminish networking effectiveness with non-Indigenous business partners. The non-Indigenous family, however, encouraged networking. The result is that the non-Indigenous networked widely, while the Indigenous networked predominantly within the dominant society (i.e., settler society). This had changed slightly in the current decade with the rise and establishment of Indigenous Chambers of Commerce, providing guidelines for the inclusion and integration of Indigenous and non-Indigenous business relationships and networks. In most instances, an imbalance of power exists where the Indigenous entrepreneur became dependent to some extent on non-Indigenous network partners. The non-Indigenous, however, saw it as a much more informal relationship, an extension of their family or their family needs. Non-Indigenous business networking was an extension of their societal interactions.

Information on Australian Indigenous entrepreneurs is generally based on some 1100 Indigenous Australian qualitative interviews and case study analyses by the author Foley (Foley 1999, 2000, 2006, 2008a, 2008b, 2012, 2013, 2017) and these entrepreneurs commence business with:

- less business expertise (Social Capital),

- lower education qualifications (Human Capital), 
- lower capital resources (Financial Capital),

- restricted access to finance,

- nominal to no access to working capital resources,

- little to no real property for bank security,

- little financial wealth, and

- nominal established commercial networks.

Perhaps the most debilitating aspect of Indigenous commercial business undertaking is the overt, covert, institutional, and lateral racism. Racism is noted as an impediment in every study by author Foley from 2000 till 2017. Non-Indigenous Australian entrepreneurs enjoy better social positioning in all nine facets of networking, as shown in Table 1, enjoying a much more positive business positioning. Non-Indigenous people do not suffer the debilitating impact of racism, which is by far the greatest hindrance to commercial activity and personal well-being experienced by most Indigenous entrepreneurs.

Table 1. Comparative analysis of Indigenous and non-Indigenous entrepreneurs.

\begin{tabular}{|c|c|c|}
\hline Dimensions & Non-Indigenous Entrepreneurs & Australian Indigenous Entrepreneurs \\
\hline $\begin{array}{l}\text { Drivers for activation of } \\
\text { relationships }\end{array}$ & $\begin{array}{l}\text { Easily obtained through initial } \\
\text { family and social networks }\end{array}$ & $\begin{array}{l}\text { A necessity-often no social or human } \\
\text { capital within own networks, therefore } \\
\text { need to obtain wider networks to } \\
\text { commence business }\end{array}$ \\
\hline View of network & Accepted as the norm & A necessity \\
\hline Role of family & $\begin{array}{l}\text { Very important as a provider of } \\
\text { startup cash }\end{array}$ & Negligible, in most cases negative. \\
\hline Dynamics & $\begin{array}{l}\text { Not hindered by cultural or } \\
\text { racial diversity }\end{array}$ & Dependence on racial acceptance \\
\hline Diversity & $\begin{array}{l}\text { Non-Indigenous people have a } \\
\text { broad cultural acceptance and are } \\
\text { not hindered by diversity }\end{array}$ & Limited \\
\hline Business relation & $\begin{array}{l}\text { Varies, no cultural dependence as } \\
\text { they are culturally unrestricted }\end{array}$ & $\begin{array}{l}\text { Dependent, therefore there is } \\
\text { a power imbalance }\end{array}$ \\
\hline $\begin{array}{l}\text { Relationship between social } \\
\text { and business spheres }\end{array}$ & Highly integrated & Often separated \\
\hline
\end{tabular}

Foley (1999) places emphasis on the limitations of social, human, and financial capital of Indigenous Australian entrepreneurs. This highlights that experiences of Australian Indigenous entrepreneurs are markedly different to those of non-Indigenous entrepreneurs. Australian Indigenous entrepreneurs have significantly lower life expectancies, as they suffer poor overall health, often characterized by medical conditions of a chronic nature, consistent in other Indigenous communities (Wood and Davidson 2011; Paredo and Mclean 2010).

Various scholars of Indigenous entrepreneurship research have highlighted an incongruence of economic and social justification (Bodle et al. 2018; Spencer et al. 2016; Foley 2017; Foley 2008a), yet few have identified the specific mechanisms and initiatives to enhance entrepreneurship education. Foley (2012) provided inferences regarding pedagogy and learning of Australian Indigenous entrepreneurship, and this paper adds to the advancement of such prior research. Colbourne (2018) identified significant opportunities for Indigenous people to build a vibrant Indigenous economy that supports sustainable economic development and well-being. He identified that hybrid ventures create a response to community needs, values, cultures, and traditions. Others have identified low levels of education, low literacy, limited access to employment opportunities, and high levels of poverty associated with Indigenous people (Wood and Davidson 2011). Others argue that a generation of Indigenous leaders has argued that passive welfare is destructive to Indigenous dignity, and that long-term economic empowerment must be built through employment and entrepreneurial activity 
(KPMG 2016). In their report, KPMG also identify the importance of education in stimulating growth and creating employment.

Onwuegbuzie (2016) provided modern scientific methods to Indigenous entrepreneurship and innovation, whereby scientific knowledge can be applied to Indigenous innovation, to result in the next generation of sustainable, cost-effective, and environmentally friendly solutions. Capel (2014) study on mindfulness, knowledge, innovation, and entrepreneurship of Indigenous people identified the prominent role of mindfulness in the development of Indigenous knowledge about entrepreneurship and innovation, and the effects such mindfulness has on Indigenous participation rates. Within this context, mindfulness calls for perceptual plus content processing and the application of information on generic knowledge. Bodle et al. (2018) further identified critical success factors related to Indigenous entrepreneurs, including social and economic measures to value Indigenous knowledge in business contexts.

Morley (2014) identifies finance and access to capital as a major constraint for Indigenous entrepreneurs, as well as the importance of government initiatives to assist Indigenous entrepreneurs in this regard. He also places emphasis on the embeddedness of culture and strong community participation in Indigenous entrepreneurship. Spencer et al. (2016) further identify specific and targeted policy support for Indigenous entrepreneurs, also identifying a need to protect their environment, nurture their community, and support traditional lifestyles.

Paredo and Mclean (2010) placed emphasis on cultural aspects regarding an inclination to employ forms of exchange as much as or more for social and cultural purposes than for material gain. They included Indigenous culture aspects of communal orientation, social aims of exchange, and kin-based social structures. The authors further postulate that in Indigenous societies, the role of communal and social goals is significantly greater than in many, perhaps most, modern industrialized societies.

Verbos et al. (2011) postulate that Indigenous peoples demonstrate a remarkable resilience in the face of generalized devastation and a determination to thrive with their unique identities intact. They most often express deeply founded spiritual relationships to the earth, as a key to healing multigenerational grief and its consequences. Such resilience and spiritual relationships result in significant value differences with regard to entrepreneurship education. The latter is discussed further in the paper.

Fuller et al. (2014) researched the traditional disadvantaged suffering of Indigenous people, resulting in health problems when participating in self-employment activities. They also place emphasis on failed funding programs, and the importance of education for Indigenous entrepreneurs. It may be noted that many scholars identify the need for entrepreneurship education and training, yet fail to appropriately identify the structure and method of such programs. Foley (2008a) identified reduced social capital for Indigenous Australians, and the importance of access to appropriate networks to enhance entrepreneurial activities. Wood and Davidson (2011) went further to identify push factors associated with Indigenous entrepreneurs, predominantly to rectify previous disadvantage through poor economic situations.

Fitzgibbons and Humphries (2011) drew inspiration regarding the increasing assertiveness in the stewardship, governance, and management of earth, water, minerals, open spaces, and urban areas regarding our understanding of intellectual property and self-expression in the arts, the provision of social services, the shaping of science, and particularly pertinent to this relationship, entrepreneurial studies, and related pedagogies.

Verbos and Humphries (2015) postulate that Indigenous wisdom requires greater attention to relational ethics through critical pedagogy, thereby encouraging reflection on the paradoxes of the market logic that permeate management education. The authors reflect from a perspective of the principles of responsible management education (PRME), particularly regarding sustainable management and development of humanity. Foley (2012) compliments this approach, stating that the 
key to successful entrepreneurship education for Indigenous peoples, from the Australian perspective, is the combination of an empowering pedagogical approach and socio-culturally relevant content.

Bajada and Trayler (2014) provided a fresh approach to Australian Indigenous business education, focusing on professional, technical, and management roles in business. Whilst such courses add significant value to empowering individuals and repositioning Indigenous people in their communities, they did not pay specific attention to the unique characteristics of Indigenous entrepreneurs (Foley 2008a). The Indigenous literature places emphasis on strong communal and tribe bonds (Foley 2012), which correlates with entrepreneurship literature about strong networks and in-group collaboration (Kozan and Akdeniz 2014).

The sparse literature on Indigenous entrepreneurship has identified a few main themes, with education being the most prominent. We now explore entrepreneurship education ecosystems as a proposed solution for many of challenges faced by Indigenous entrepreneurs. Our emergent enquiry places emphasis on entrepreneurship education as an enhancer of human capital (and in turn, of social and financial capital). Since we have highlighted the definition of Indigenous entrepreneurship appropriate for this study, with inference to the integration of the business environment and peculiarities to Australian Indigenous entrepreneurs (see Table 1), we now provide a link to developing Indigenous entrepreneurship education ecosystems. We postulate that such development enhances a conducive business environment toward accelerating Indigenous entrepreneurship. We first consider generic entrepreneurship education ecosystems (Section 3), and then contextualize this within an Indigenous entrepreneurship context (Section 4).

\section{Entrepreneurship Education Ecosystems}

Entrepreneurship education ecosystems (EEEs) have, in the last few years, received promising research within non-Indigenous entrepreneurship education (Maritz 2017), yet are non-existent within Indigenous entrepreneurship education. We provide an overview of EEEs, with the aim to integrate them within an Indigenous entrepreneurship context in the discussion section.

The formation of entrepreneurial ecosystems is recognized as an activity that can produce economic development and community revitalization (Brush 2014). Similarly, social entrepreneurship is also an activity that is receiving significant attention, because of its potential for addressing social and economic problems (Roundy 2017). Our study advances the integration of entrepreneurship ecosystems and social entrepreneurship to develop mechanisms for Indigenous people to learn about entrepreneurship. We refer to these mechanisms as EEEs.

EEEs refer to those dynamic systems of integrated networks and associations aligned to entrepreneurship education programs (EEPs). EEPs are integrated research and scholarship components of entrepreneurship education, whereby entrepreneurship skills and knowledge are disseminated to various stakeholders (Neck and Corbett 2018; Maritz 2017). Components of EEPs are dynamic and change according to context, but most generally consist of entrepreneurship ecosystems, outcomes, objectives, assessments, contextualization, content, pedagogy, and audience (Maritz 2017). Each component is briefly expanded below, with inferences (permission granted) directly from the Maritz (Maritz 2017, Figure 1, p. 477) research on entrepreneurship education programs.

\subsection{Entrepreneurship Ecosystem}

This component refers to integrating ecosystem components of policy and finance, culture and support, human capital and markets, the entrepreneurial university, accelerators and incubators, science parks, governments, start-up communities, and national entrepreneurship systems.

\subsection{Outcomes}

This component consists of self-efficacy, intentionality, venture creation, enterprise skills, entrepreneurial orientation, and threshold learning outcomes, as well as start-ups and technology transfer. 


\subsection{Objectives}

Objectives include pedagogical, social, economic, entrepreneurial mindset, knowledge, skills, attitudes, and attributes.

\subsection{Assessment}

This component includes causation, effectuation, bricolage, entrepreneurial orientation, new ventures, self-efficacy, and intentionality.

\subsection{Contextualisation}

This idea consists of justification, legitimization, validation, dynamic dimension integration, geographic, qualified scholars, flexibility, adaptability, and contemporary approaches.

\subsection{Content}

Content includes design thinking, lean start-up, business model design, entrepreneurship process, entrepreneurial mindset, learning from entrepreneurs, learning from failure, enterprise education, and type of entrepreneurship.

\subsection{Pedagogy}

This idea includes online and blended pedagogy, authentic alignment, cross-disciplinary (such as STEM), student-centred, EE by design, traditional pedagogy, inquiry-based learning, and experiential and collaborative learning.

\subsection{Audience}

The audience consists of the diversity of stakeholders, student diversity, internationalization, EE associations, type of entrepreneur, and type of entrepreneurship.

Neck and Corbett (2018) introduce EE as being at a tipping point, conceding that the emergence of entrepreneurship has occurred so rapidly that it has outpaced our understanding of what should be taught by entrerpreneurship educators, how it should be taught, and how outcomes should be assessed. Many initiatives internationally have addressed this tipping point, a prominent example being the Guidance for UK Higher Education Providers (QAA 2018). This publication succinctly provides aims and vision for enterprise and entrepreneurship education in a UK context, together with providing generic inferences on the student learning experience, including the learning journey, entrepreneurial effectiveness, enterprise awareness, developing an entrepreneurial mindset, developing entrepreneurial capability, entrepreneurial effectiveness, and graduate outcomes. Whilst these student learning experiences are mirrored in the Neck and Corbett (2018) and Maritz (2017) frameworks, none provide significant guidelines for specific target audiences, such as Indigeneous entrepreneurs. Generic adult learning is most often enhanced through the appropriate integration of androgy, pedagoy, problem-based learning, and experiential learning (Neck and Corbett 2018). One may assume a one-fit model is applicable to all learners, but the scholarship of entrepreneurship learning and teaching has certainly provided the inference that varied learner profiles necessitate specific learning initiatives (Balan et al. 2017). This research proposes specific requirements in learning entrepreneurship, based upon specific Indigenous entrepreneurship nuances.

Brush (2014) originally postulated EEEs from the perspective of university-based and internal dimensions. The former related to the alignment of institutional objectives and access to the university and other regional resources (also referenced to as external). Internal perspectives include EEPs, and more specifically, co-curricular programs and initiatives and research within domains of culture, resources, stakeholders, and infrastructure. Mueller and Toutain (2015) subsequently developed their EEE model, consisting of motivation resulting from dimensions of framework, spaces, pedagogies, and connections. Further expanding EEEs, Belitski and Heron (2017) provided a systematic literature 
review on entrepreneurship ecosystems, developing their model consisting of dynamic dimensions of stakeholder engagement (universities, governments, and individuals), entrepreneurship education culture, outreach, and formal and informal networks. These three approaches over as many years should not be seen as linear, but dynamic and constantly evolving.

We now discuss the integration of Indigenous entrepreneurs within the context of EEEs, based upon our definition and characteristics of Indigenous entrepreneurs in Figure 1.

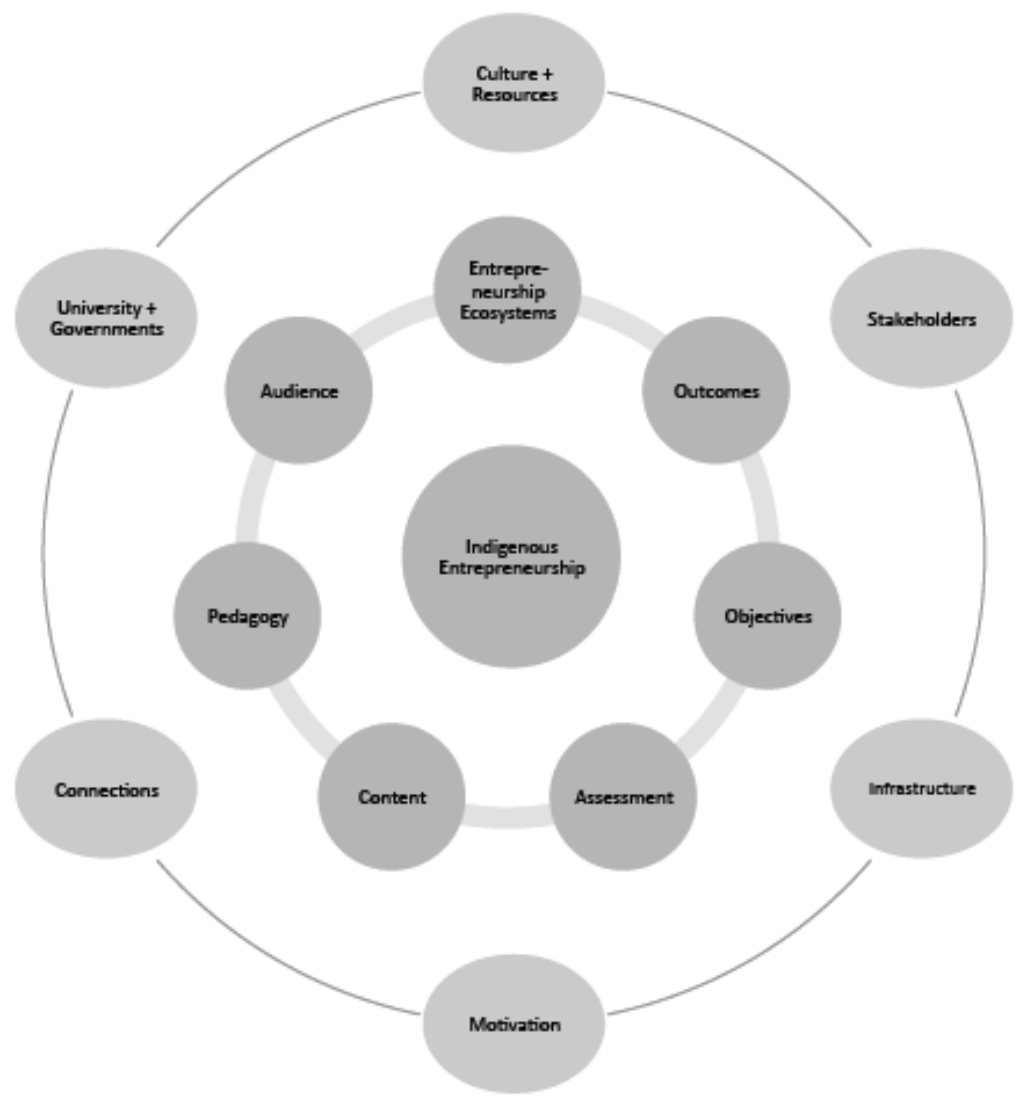

Figure 1. A conceptual framework of Indigenous Australian entrepreneurship education ecosystems (IEEEs). Source: Maritz (2017) and Belitski and Heron (2017).

\section{Discussion}

We previously identified Indigenous entrepreneurship as unique and markedly different to non-Indigenous entrepreneurship, with highlights from this research including dimensions of drivers for activating relationships, views on networks, the role of family, dynamics, diversity, business relationships, and relationships between social and business spheres (see Table 1). In this section, we identify the interaction of Indigenous entrepreneurs within their communities and environments, and ultimately within their IEEEs.

Prior to the Indigenous inference, we place emphasis on generic adult learning with regard to entrepreneurship content. Neck and Corbett (2018) postulate that andragogy (how adults learn) rather than pedagogy (how children learn), coupled with problem-based learning, is a foundational element of most EE courses. Some related teaching theories include self-directed learning, readiness to learn, and learning through practice. As a priori, this research proposes that Indigenous entrepreneurs have distinct androgogical learning fundamentals, which may not align directly with mainstream entrepreneurship education.

We commence with contextual inferences regarding Indigenous entrepreneurs and EEPs. 


\subsection{Entrepreneurship Ecosystem}

The introduction and dominance of the Western legal and economic systems not only eliminated First Nation peoples' traditional economy, but also destroyed their social systems (Bodle et al. 2018). As such, Indigenous people remain in the margins, with little political and social power, whilst western dominance continues to flourish. Transformation to revived opportunities has, however, been observed through various social entrepreneurship initiatives (Spencer et al. 2016), providing a successful community-based pathway for increasing Indigenous economic participation on local terms at a time of regional economic decline and high levels of Indigenous unemployment nationally. The continuing colonial dominance in Australian society has ensured that the Indigenous entrepreneur exists within a system that has little to no cultural relevance, and also that their debtors are mostly non-Indigenous, their creditors and financier are non-Indigenous (with the exception of occasional Indigenous Business Australia funding), and their business model within this cultural subjugating space is also non-Indigenous (Foley 2017). Communal and social goals are most often significant in Indigenous communities, inclusive of Indigenous cultural aspects of communal orientation, kin-based social structures, and social aims of exchange (Paredo and Mclean 2010).

Our study also found that Indigenous Australian entrepreneurs, when compared to other mainstream entrepreneurs, have less social capital, lower human capital, lower financial capital, limited access to capital, nominal access to working capital, and overall hardship and lack of inclusion to mainstream entrepreneurship ecosystems (Foley 2006). Hence, an opportunity exists to develop a framework specifically for the unique requirements of Indigenous entrepreneurs.

\subsection{Outcomes}

Critical success factors in managing sustainable Indigenous businesses in Australia, the economic and social values that Indigenous communities attach to intangible Indigenous cultural heritage (ICH) and Indigenous intellectual property (ICIP) may be both recognized and realized as assets (Bodle et al. 2018). Indigenous entrepreneurship represents a significant opportunity for Indigenous people to build vibrant Indigenous-led economies that support sustainable economic and social well-being. It is a means by which they can design, develop, and maintain Indigenous economic and social systems (Colbourne 2018). Greater attention to the world views held by Indigenous peoples provides a window to values that may well be universal, but which have been overshadowed by the valorization of a particular set of western values that served the aspirations of capitalist orientations well. Entrepreneurship may well be a way of enhancing and communicating these Indigenous values to the world (Fitzgibbons and Humphries 2011).

Enhancing social and human capital in Indigenous entrepreneurs requires unique and targeted outcomes (Foley 2000, 2006, 2008b).

\subsection{Objectives}

Low entrepreneurship participation rates prevail and illustrate the enormous difficulties that continue to be faced by Indigenous people in Australian society (Wood and Davidson 2011).

Much of what drives entrepreneurship or self-determination is the skill and capacity that are derived through an effective level of education (Bajada and Trayler 2014). Drivers for activation of relationships are a unique requirement for Indigenous entrepreneurs, usually necessitating their own networks (Foley 2000, 2008b).

\subsection{Assessment}

Much of the innovations derived from Indigenous traditional knowledge occur outside traditional research and development structures. These inventions have the potential to solve contemporary problems and tend to be cost-effective, environmentally friendly, and sustainable. This is because Indigenous people usually use low-cost inputs and have an intimate knowledge of the ecosystem 
and how to preserve it (Onwuegbuzie 2016). Dependence on racial acceptance is part of Indigenous dynamics (Foley 2006).

\subsection{Contextualisation}

A distinctive characteristic of Indigenous entrepreneurship is the desire to protect the environment, nurture the community, and support traditional lifestyles. The primary goal is not usually high growth or profit-making (Verbos and Humphries 2015). Social entrepreneurship is often a means to an end in Indigenous enterprise, and a result of individuals' interests, capabilities, preferred lifestyles of community members, control of traditional lands, health and wellbeing, and other social programs (Anderson et al. 2006). Indigenous entrepreneurs often encounter power imbalances in business relationships (Foley 2000, 2008b).

\subsection{Content}

Many Indigenous studies have identified resource bricolage integration as primary entrepreneurship enabler (Wood and Davidson 2011) with a suggestion of andragogy and problem-based learning, via self-directed learning, readiness to learn, and learning through practice (Neck and Corbett 2018). Mindfulness, associated with content processing and application of information on generic knowledge system integration, may overcome shortcomings in both systems (Onwuegbuzie 2016). Limited diversity of Indigenous entrepreneurs provides opportunity for network content learning (Foley 2006).

\subsection{Pedagogy}

Social enterprises should develop their capabilities in resource bricolage in order to achieve their goals in the long term. From an Indigenous perspective, bricolage relates to the innovative application of scarce resources to meet a social mission (Wood and Davidson 2011). Indigenous knowledge and mainstream knowledge system integration may overcome shortcomings in both systems (Onwuegbuzie 2016). Verbos and Humphries (2015) place emphasis on the importance of Indigenous sustainable management and development of humanity (associated to PRME), which enhances the need for formal entrepreneurship education among Indigenous people. Pedagogy associated to role of family and networks is a requirement (Foley 2006).

Critical pedagogy encourages reflection on the paradoxes of the market logic of traditional management education (Verbos and Humphries 2015), necessitating a holistic view of pedagogy in IEEEs.

\subsection{Audience}

Indigenous entrepreneurs experience strong reciprocity that characterizes the social capital between stakeholders, enhancing effective social entrepreneurship and strengthening social capital in communities (Anderson et al. 2006). Strong in-group networks in Indigenous communities correlate with significant network strength of entrepreneurship literature and growth variables in successful ventures (Kozan and Akdeniz 2014). Foley (2012) postulated that Indigenous people are increasingly undertaking trade-based or structured education, and this is linked to rising levels of Indigenous entrepreneurial success. The Indigenous Chambers of Commerce may also be engaged to enhance the networking capabilities of Australian Indigenous entrepreneurs.

We now expand the discussion to dynamic dimensions of EEEs.

\subsection{Culture, Resources, Stakeholders, and Infrastructure}

Reduced social capital for Indigenous Australians results in active social networking being a necessity of their basic entrepreneurial endeavours (Foley 2008a). Entrepreneurs embedded in a minority culture interact within their dominant cultures simultaneously, often including 
undercapitalization, recurring liquidity pressures, inability to access capital on reasonable terms and conditions, recurring difficulties in servicing debt, inadequate margins, and poor asset utilization (Fuller et al. 2014). Many studies have commented on the significant complex social and cultural context within which some Indigenous peoples share. Having culture embedded in community-based enterprises is vital for success, as is good governance and strong community participation (Morley 2014) An integrated approach is required for Indigenous entrepreneurs to utilize resources in the pursuit of self-determination and economic sustainability (Foley 2006; Hindle and Lansdowne 2005).

\subsection{Motivation, Pedagogies, and Connections}

Indigenous entrepreneurship is most often connected with the notions of community-based economic development, and is usually viewed by elders and governments as such, rather than as a strictly individual nature, as in non-Indigenous entrepreneurship (Peredo et al. 2004): "Supporting entrepreneurism, financial literacy, and better educational attainment among Australia's First people is a much better use of taxpayer funds than passive welfare, which most Indigenous leaders agree is poison to the dignity and self-esteem of their communities" (KPMG 2016).

Verbos et al. (2011) identified values differences between dominant values in management, education, and Native American Indigenous values. These value differences closely resemble those of Australian Indigenous peoples. Dominant values in management education are listed with Indigenous values in italics. From a human behaviour perspective, dominant values include rationality and self-interest, in contrast to generosity and modesty. Environment includes natural resources to be exploited for profit, in contrast to nature as spiritual and practical, maintaining harmony and balance. The individual motivation of maximizing self-interest, money, and status is contradicted by contributions to well-being of family/tribe, respect, and humility. Self-construal values of individualism are replaced by collectivism and respect for elders. Decision-making made through formal authority is replaced by reflection and participation, and formal (title-based) property rights are replaced by use or communal requirements. Traditional organization is hierarchical, whereas Indigenous people effect greater egalitarianism (circle), with goals of efficiency, effectiveness, and profits replaced by providing employment and enhancing community value. This paper integrates these Indigenous values, in particular the notion of creating employment through entrepreneurship, viewed as an extension of the traditional provision of employment.

\subsection{Universities, Governments, and Individuals}

As Paredo and Mclean (2010) describe, "Indigenous people throughout the world suffer from chronic poverty, lower education levels, and poor health. The 'second wave' of indigenous funding, after direct economic assistance from outside, lies in Indigenous efforts to rebuild their 'nations' and improve their lot through entrepreneurial enterprise". In this paper, this process is referred to as Indigenous Australian entrepreneurship. There are various government initiatives targeted at Indigenous entrepreneurs, including specialized training and development with regard to access to finance, business advice, business idea testing, and financial literacy testing (Morley 2014). Education is the key to Indigenous employment, and must be invested in heavily (KPMG 2016). The Australian government is currently overhauling its support for Indigenous businesses by reforming Indigenous Business Australia (IBA) and consulting on a new Indigenous Entrepreneurs Capital Scheme. IBA has historically been the conduit within which government can provide funding to advance policy for individual wealth accumulation for Indigenous Australians, through financial support in owning homes and businesses and investing in commercial ventures that generate income.

Figure 1 provides a conceptual framework of the components of IEEEs, developed from the integration of components of EEPs (Maritz 2017), EEEs (Brush 2014; Mueller and Toutain 2015), and the emergent inquiry from this research. Central to the framework is the research and scholarship on Australian Indigenous entrepreneurship, identifying specific nuances in Indigenous entrepreneurship 
(such as social and community motives), flanked by dimensions of EEPs and within dimensions of EEEs. As with non-Indigenous entrepreneurship, contextualization plays a similar if not a more pronounced role. This is particularly the case regarding geographical and Indigenous communities.

The conceptual framework has its core in the foundation of Indigenous entrepreneurship, with contextualization of the definition adopted for this research. Concentric circles identify various building levels of the framework, (Sections 2 and 3 of this research). The next layer depicts elements of EEPs, incorporating entrepreneurship ecosystems as a guiding initiative to incorporate the non-linearity of components of outcomes, objectives, assessment, content, pedagogy, and audience. The final layer of the conceptual framework incorporates Indigenous entrepreneurship specifics, built around culture and resources, stakeholders, infrastructure, motivation, connections, universities and government. These specific dimensions further resonate with the dimensions of variation identified in Table 1, together with the identified scope of Indigenous entrepreneurship around social, human, and financial capital. We do not see this framework as exhaustive of the Indigenous entrepreneurship debate, but as an addition and enhancement to the scholarship of Indigenous Australian entrepreneurship education.

\section{Conclusions and Implications}

Australian Indigenous entrepreneurs are at the forefront of change and innovation in Australia, and with Indigenous vision and entrepreneurship, have the power to enrich their culture for themselves and share it with the world. According to IBA, there are about 12,000 Indigenous businesses in Australia, with all government expectations predicting a sharp increase in such start-ups. These Indigenous entrepreneurs are primarily utilizing resources in the pursuit of self-determination and economic sustainability.

It is evident that entrepreneurship ecosystems, and the subsequent design and development of associated entrepreneurship education ecosystems, have direct and positive influences on the prosperity of economic development and social enhancement. This paper examined Indigenous entrepreneurship in an Australian context and ways of developing entrepreneurship education ecosystems within this context. We are mindful of Indigenous nuances particular to Australian Indigenous people, inclusive of Indigenous value perspectives, including Indigenous knowledge, wisdom, resilience, and the cultural captivity of entrepreneurship and Indigenous culture. Such integrative cultural influences include communal orientation, kin-based social structures, and social aims of exchange. This research provides the argument that in most Indigenous societies, the role of communal and social goals is greater than in many, perhaps most modern industrialized societies. This necessitates goal design-oriented IEEEs, catering for distinct business requirements of Indigenous nascent entrepreneurs. This is not only evidenced from emergent enquiry in this research, highlighting deficiencies of Indigenous entrepreneurs in areas of social, human, and financial capital, but also within the context of dimensional differences between mainstream entrepreneurs and Indigenous entrepreneurs. Table 1 identified seven of these dimensions, from relationships, networks, role of family, dynamics, diversity, and business relationships to relationships between social and business spheres.

Figure 1 shows a comprehensive framework of components of a conceptualization of an entrepreneurship education ecosystem for Indigenous entrepreneurs, based upon our review of current available literature. We found that Australian Indigenous entrepreneurs were strongly linked to the need to improve their economic situation, predominantly within social- and community-driven motives. We identify outlying components consisting of culture and resources, stakeholders, infrastructure, motivation, connections (community), and university and governments. We also adopted a validated entrepreneurship education program model, as developed by Maritz (2017). This adoption identified specific nuances applicable to Indigenous entrepreneurs, consisting of the entrepreneurship ecosystem, outcomes, objectives, assessment, content, pedagogy, and audience.

Implications for the body of knowledge include an extension to literature on Indigenous entrepreneurship, plus a novel and first-of-its-kind study on Indigenous entrepreneurship education 
and ecosystems. Implications for practice include guidelines and a framework for entrepreneurship educators, Indigenous entrepreneurs, policy makers, and ecosystem stakeholders wishing to expand and enhance the entrepreneurial skills of Australian Indigenous entrepreneurs. We provide a concentric approach to add dialogue at various levels of the framework. The possible creation of a culturally acceptable Indigenous business model that is flexible and adaptable to varied applications, as well as an opportunity for further research, includes validating and testing the EEE Framework within an international Indigenous entrepreneurship context. Lastly, network peculiarities of Australian Indigenous entrepreneurs may be explored with other Indigenous entrepreneurs on an international level.

Author Contributions: A.M. and D.F. jointly contributed to the development of this research.

Acknowledgments: The editorial team and reviewers for the professional recommendations leading to the enhancement of this paper.

Conflicts of Interest: The authors declare no conflict of interest.

\section{References}

Anderson, Robert B., Leo Paul Dana, and Teresa E. Dana. 2006. Indigenous land rights, entrepreneurship, and economic development in Canada. Journal of World Business 41: 45-55. [CrossRef]

Bajada, Christopher, and Rowan Trayler. 2014. A fresh approach to indigenous business education. Education + Training 56: 613-34. [CrossRef]

Balan, Peter, Alex Maritz, and Matthew McKinlay. 2017. A structured method for innovation in entrepreneurship pedagogies. Education + Training 60: 428-63.

Belitski, Maksim, and Keith Heron. 2017. Expanding entrepreneurship education ecosystems. Journal of Management Development 36: 163-77. [CrossRef]

Bodle, Kerry, Mark Brimble, Scott Keith W Weaven, Lorelle Frazer, and Levon Blue. 2018. Critical success factors in manageing sustainable indigenous businesses in Australia. Pacific Accounting Review 30: 35-51. [CrossRef]

Brush, Candida G. 2014. Exploring the concept of an entrepreneurship education ecosystem. In Innovative Pathways for University Entrepreneurship in the 21st Century. New York: Emerald Group Publishing, vol. 24, pp. 25-39.

Capel, Celine. 2014. Mindfulness, indigenous knowledge, indigenous innovations and entrepreneurship. Journal of Research in Marketing and Entrepreneurship 16: 63-83. [CrossRef]

Colbourne, Rick. 2018. Indigenous Entrepreneurship and Hybrid Ventures. Advances in Entrepreneurship, Firm Emergence and Growth 19: 93-149.

Dana, Leo-Paul. 2005. Editorial. Journal of Small Business \& Entrepreneurship 18: v-vi.

Dana, Leo-Paul. 2007. Toward a multidisciplinary definition of indigenous entrepreneurship. In International Handbook of Research on Indigenous Entrepreneurship. Cheltenham: Edward Elgar.

Fitzgibbons, Dale E., and Maria Humphries. 2011. Enhancing the circle of life: Management education and Indigenous knowledge. Journal of Management Education 35: 3-7. [CrossRef]

Foley, Dennis. 1999. A case study Analysis of Succesful Indigenous Entrepreneurs. Unpublished Master's dissertation, Griffith University, Brisbane, Australia, July 26.

Foley, Dennis. 2000. Successful Indigenous Australian Entrepreneurs: A Case Study Analysis, Aboriginal and Torres Strait Islander Studies Unit Research Report Series 4. Brisbane: Aboriginal and Torres Strait Islander Studies Unit, University of Queensland.

Foley, Dennis. 2006. Does Business Success make you any less Indigenous? In Regional Frontiers of Entrepreneurship Research 2006: Proceedings of the Third Annual AGSE International Entrepreneurship Research Exchange. Edited by Murray Gillen, Butler John, Alastair Campbell, Per Davidsson, Howard Frederick, Kevin Hindle, Noel Lindsay, Alex Maritz, Claire Massey, Francina Reihana and et al. Hawthorn: Swinburne Press, pp. 241-57.

Foley, Dennis. 2008a. Does culture and social capital impact on the networking attributes of indigenous entrepreneurs? Journal of Enterprising Communities 2: 204-24. [CrossRef]

Foley, Dennis. 2008b. What Determines the bottom Line for Maori Tourism SMEs? Small Enterprise Research. The Journal of SEAANZ 16: 86-97. 
Foley, Dennis. 2012. Teaching entrepreneurship to Indigenous and other minorities: towards a strong sense of self, tangible skills and active participation within society. Journal of Business Diversity 12: 59-70.

Foley, Dennis. 2013. Jus Sanguinis: the root of contention in determining what is an Australian Aboriginal Business. Indigenous Law Bulletin 8: 25-9.

Foley, Dennis. 2017. The Dark side of Responsible Business Management. In Indigenous Aspirations and Rights: The Case for Responsible Business and Management. Edited by Amy Klemm Verbos, Ella Henry and Ann Maria Peredo. Auckland: Greenleaf Publishing, chp. 2. pp. 22-33.

Foley, Dennis, and Beverley Hunter. 2013. What is an Indigenous Australian Business? Journal of Australian Indigenous Issues 16: 66-74.

Fuller, Don, Peter Dansie, Merrick Jones, and Scott Holmes. 2014. Indigenous Australians and Self-Employment. Small Enterprise Research 7: 5-28. [CrossRef]

Hindle, Kevin, and Michele Lansdowne. 2005. Brave Spirits on new paths: toward a globally relevant paradigm of indigenous entrepreneurship research. Journal of Small Business and Entrepreneurship 18: 131-42. [CrossRef]

Kozan, Kamil M., and Levent Akdeniz. 2014. Role of strong versus weak networks in small business growth in an emerging economy. Administrative Sciences 4: 35-50. [CrossRef]

KPMG. 2016. Collaborative Ideas for Igniting the Indigenous Economy. Sydney: KPMG, October.

Maritz, Alex. 2017. Illuminating the black box of entrepreneurship education programs: Part 2. Education + Training 599: 471-82. [CrossRef]

Morley, Sam. 2014. Success factors for Indigenous Entrepreneurs and Community-Based Entrepreneurs; Sydney Australian Government: Australian Institute of Health and Welfare, pp. 1-17.

Mueller, Sabine, and Olivier Toutain. 2015. The Outward Looking School and its Ecosystem. Stockholm: OECD, European Commission.

Neck, Heide, and Andrew Corbett. 2018. The Scholarship of Teaching and Learning. Entrepreneurship Education and Padagogy 10: 8-41. [CrossRef]

Onwuegbuzie, Henrietta. 2016. A 21st century paradigm for entrepreneurs and policy makers: Applying modern scientific methods to indigenous innovation. Contemporary Issues in Entrepreneurship Research 6: 103-26.

Paredo, Ana Maria, and Murdith Mclean. 2010. Indigenous development and the cultural captivity of entrepreneurship. Business \& Society 52: 592-620.

Peredo, Ana Maria, Robert B. Anderson, Craig Galbraith, Benson Honig, and Léo-Paul Dana. 2004. Towards a theory of Indigenous entrepreneurship. International Journal of Entrepreneurship and Small Business 1: 18. [CrossRef]

QAA. 2018. Entterprsie and Entrepreneurship Education: Guidance for UK Higher Education Providers. Gloucester: The Qauality Assurance Agency for Higher Education.

Roundy, Philip P. 2017. Social entrepreneurship and entrepreneurial ecosystems: Complementary or disjoint phenomena? International Journal of Social Economics 44: 1252-67. [CrossRef]

Spencer, Rochelle, Martin Brueckner, Gareth Wise, and Banduk Marika. 2016. Australian indigenous social enterprise: measuring performance. Journal of Enterprising Communities 10: 397-424. [CrossRef]

Verbos, Amy Klemm, and Maria T. Humphries. 2015. Indigenous wisdom and PRME: inclusion or illusion. Journal of Management Development 34: 1-17. [CrossRef]

Verbos, Amy Klemm, Joe S. Gladstone, and Deanna M. Kennedy. 2011. Native American values and management education: Envisioning an inclusive viryuous circle. Journal of Management Education 35: 1-26. [CrossRef]

Wood, Glenice J., and Marilyn J. Davidson. 2011. A review of male and female Australian indigenous entrepreneurs: Disadvantaged past—Promising future? Gender in Management: An International Journal 26: 311-36. [CrossRef]

(C) 2018 by the authors. Licensee MDPI, Basel, Switzerland. This article is an open access article distributed under the terms and conditions of the Creative Commons Attribution (CC BY) license (http:/ / creativecommons.org/licenses/by/4.0/). 